\title{
Modelo Alternativo para o Controle da Esquistossomose: Estado Atual do Projeto no Estado do Espírito Santo, Brasil ${ }^{1}$
} An Alternative Model for Schistosomiasis Control: The Present Status of
the Project in the State of Espirito Santo, Brazil

\author{
Frederico S. Barbosa 2; Oswaldo J. da Cruz 2; Eliane Hollanda ${ }^{2}$; Sandra A. V. Siqueira ${ }^{2}$; \\ Maria Alice P. de Carvalho ${ }^{2}$; Mauro L. Gomes ${ }^{3}$ \& Andrea S. de Almeida ${ }^{2}$
}

BARBOSA, F. S.; CRUZ, O.J.; HOLLANDA, E.; SIQUEIRA, S.A.V.; CA RVA LHO, M.A. P.; GOMES, M. L. \& ALMEIDA, A. S. An Alternative Model for Schistosomiasis Control: The Present Status of the Project in the State of Espírito Santo, B razil. Cad. Saúde Públ., Rio de Janeiro, 9 (1): 85-89, jan/mar, 1993.

A $n$ intervention study for schistosomiasis control is being carried out in the county of Afonso Cláudio, state of Espírito Santo, B razil, having begun in February 1992. This study is an alternative response to classical control methods. The project is being developed using an interdisciplinary approach and involves both research and service institutions. The organization of health services at the primary care level is part of the project. Participant observation is seen as the methodological point of departure for guiding data collection and analysis and the intervention process in local reality. Control methods are restricted to the medical treatment given to all infected individuals and to improvements in the sanitation facilities available in the area. These methods are obviously integrated with the above-mentioned social actions.

Consisting of three phases - pre-control, control (intervention), and final evaluation - the project is now in its intervention phase, lasting approximately three years.

Keywords: Schistosomiasis; Epidemiology; Control; Espírito Santo; B razil

Programas regionais e a nível nacional, têm sido postos em prática em vários países onde as esquistossomoses são endêmicas. Estes programas têm sido marcados por algumas características, enfatizando-se medidas específicas de controle e, mais recentemente, tentativas no sentido de integrar estas medidas. Em algumas ocasiões, estes programas procuraram incorporar obras de saneamento básico, contemplando ainda ações educacionais e a participação

\footnotetext{
1 Trabalho financiado pela Fundação Oswaldo Cruz, Fundação Nacional de Saúde, Secretaria de Saúde do Estado do Espírito Santo e a Prefeitura do M unicípio de A fonso Cláudio, Espírito Santo.

2 Escola Nacional de Saúde Pública, Fundação Oswaldo Cruz. Rua Leopoldo Bulhões, 1480, 21041-210, Rio de Janeiro, RJ, Brasil.

${ }_{3}^{3}$ Escola Politécnica de Saúde J oaquim Venâncio,

Fundação Oswaldo Cruz. Rua Leopoldo Bulhões, 1480,

21041-210, Rio de Janeiro, RJ, B rasil.
}

comunitária, ou mencionando a integração com os serviços locais de saúde. Entretanto, até o momento, as ações de controle destes programas têm sido, na sua maioria, verticalizadas, não sendo avaliadas em toda a sua extensão. Este assunto é discutido com algum detalhe em publicação recente (Barbosa \& Coimbra, 1992).

O presente projeto representa uma proposta alternativa aos atuais programas de controle e é, antes de tudo, um trabalho de pesquisa controlado e executado em uma área limitada, para que o mesmo possa ser avaliado em comparação com outras áreas do estado do Espírito Santo sujeitas a medidas clássicas de controle (Barbosa, 1991). Ele representa, também, um esforço de integração interdisciplinar de diferentes setores da Fundação Oswaldo Cruz (Fiocruz) nas áreas de epidemiologia, ciências biológicas, ciências sociais, organização de sistemas de saúde a nível local e treinamento de 
pessoal auxiliar, todas com objetivos comuns. Além disso, o programa vem sendo desenvolvido em uma integração multi-institucional que envolve a Fiocruz, a Fundação Nacional de Saúde (FNS) e as Secretarias Estadual e Municipal de Saúde do Espírito Santo.

O objetivo geral do projeto é a construção de um modelo de controle da esquistossomose desenvolvido em integração com os serviços locais de saúde e com a participação ativa da comunidade, modelo este capaz de reduzir substancialmente os indicadores de prevalência e de incidência, bem como a intensidade da infecção esquistossomótica na área de estudo. $\mathrm{O}$ modelo proposto é mais ambicioso, uma vez que, utilizando a esquistossomose como pontade-lança, está envolvido em todos os aspectos da saúde e bem-estar da comunidade.

Neste projeto, o enfrentamento da esquistossomose é visto numa perspectiva social que privilegia dois fatores de máxima importância para o controle da endemia:

- O saber acumulado pela população local acerca do processo SAÚDE-DOENÇA e sua compreensão do que seja a esquistossomose, em particular;

- A relação estabelecida entre pesquisador e pesquisado, visando a construção de um conhecimento coletivo resultante da discussão sobre o tema.

A pesquisa participante tem sido o ponto de partida metodológico que baliza os procedimentos de coleta e análise de dados, e os de intervenção na realidade local. Neste tipo de trabalho, a população "pesquisada" tem uma participação ativa na geração de conhecimentos: ela não apenas toma ciência dos resultados do trabalho, mas efetivamente ajuda a elaborá-los. Este processo é visto como uma forma de educação coletiva, onde a população-alvo da atividade torna-se co-autora da análise e das propostas de intervenção na realidade.

A noção de que os componentes sociais e econômicos são relevantes para o controle da esquistossomose é antiga, embora nem sempre tenha sido bem compreendida em sua extensão e profundidade. É também conhecido há algum tempo o conceito de focalidade na transmissão da esquistossomose. A noção de focalidade obriga a que se dê a devida atenção à condução das medidas de controle da esquistossomose, procurando influir de modo decisivo no complexo das relações muito estreitas que se estabelecem entre o homem e seu micro-ambiente, sem se esquecer, todavia, que a ocupação desigual do espaço é consequiência da organização política/econômica da sociedade.

O projeto propõe a integração efetiva com os programas de saúde e desenvolvimento social, envolvendo instituições oficiais ou privadas e a sociedade civil, através de suas organizações leigas ou religiosas. A integração vem sendo feita paulatinamente, enquanto procura-se assessorar a Secretaria Municipal de Saúde na reformulação de seus serviços de saúde, de acordo com o Sistema Único de Saúde (SUS), contido na Lei $\mathrm{n}^{\circ} 4.317$, de 04 de janeiro de 1990, e vários outros dispositivos, como o Decreto $n^{\circ}$ 3011-N, de 06 de junho de 1990, que homologam o Sistema Estadual de Saúde para o Espírito Santo (SES-ES, 1990).

O projeto de pesquisa em curso rejeitou ações consideradas pouco eficazes, como o tratamento medicamentoso em massa e o uso de moluscicidas. Este último, além de oneroso, é também poluidor do meio ambiente (Barbosa \& Coimbra, 1992).

As ações interventivas, além das de ordem geral acima mencionadas (mobilização comunitária e organização dos serviços locais de saúde), são dirigidas à terapêutica individualizada de todos os portadores de ovos de Schistosoma mansoni em ciclos anuais e à melhoria das condições de saneamento, com a construção de um sistema de proteção de fontes de água de encosta ou de fundo de vale, construção de poços rasos escavados e de tanques de lavar roupa, e construção de fossas secas ou absorventes, detalhadas em documento produzido pela Fundação Nacional de Saúde (FNS, 1992) para este projeto.

$\mathrm{O}$ projeto está em andamento em uma área rural limitada, selecionada de acordo com critérios preestabelecidos (Barbosa, 1991), nas proximidades da cidade de Afonso Cláudio, região serrana do Espírito Santo. Nas áreas de estudo estão situadas 10 localidades, com uma população total de 2.383 habitantes e suas respectivas taxas de prevalência para o ano de 1991 (Tabela 1). 
TABELA 1. Prevalência da Esquistossomose na Área Operacional do projeto de Controle da Endemia, Espírito Santo, Município de Afonso Cláudio. População Total, 1991

\begin{tabular}{lccc}
\hline \hline Localidade & $\begin{array}{c}\text { População } \\
\text { Presente }\end{array}$ & Positivos & $\begin{array}{c}\% \\
\text { Infectados }\end{array}$ \\
\hline 1. Vargem Grande & 400 & 106 & 26,4 \\
2. Vargedo & 233 & 76 & 32,7 \\
3. Córrego de São Pedro & 247 & 61 & 24,6 \\
4. Ribeirão do Costa & 122 & 61 & 50,0 \\
5. Córrego de Santo Antônio 1o. & 463 & 65 & 14,1 \\
6. Ribeirão dos Pontões & 539 & 89 & 16,6 \\
7. Córrego Bom Sera & 92 & 23 & 25,2 \\
8. Córrego Rancharia & 27 & 6 & 21,7 \\
9. Cab. Córrego Bom Sera & 109 & 23 & 21,2 \\
10. Córrego Kuster & 151 & 28 & 18,6 \\
\hline Total & 2.383 & 538 & 22,5 \\
\hline \hline
\end{tabular}

Fonte: Fundação Nacional de Saúde.

O projeto teve início em fevereiro de 1992 e se desenvolve em três fases: pré-controle ( 8 meses), intervenção (36 meses) e avaliação final (6 meses), de acordo com o cronograma abaixo:

\section{FASES \\ Pré-Controle \\ Intervenção \\ Avaliação Final}

$1992 \bowtie 1993$

1994

1995

$\triangle 996 \Sigma$

No momento, o projeto encontra-se no início de sua fase de intervenção, que começou efetivamente em outubro de 1992.

$\mathrm{Na}$ fase de pré-controle (fevereiro a setembro de 1992) foram iniciados os primeiros contatos com a população e as instituições locais, organizando-se reuniões periódicas com a comunidade onde o projeto é discutido, uma vez que pretende-se contar com a efetiva adesão dos grupos locais organizados.

Em relação ao modelo de saúde a ser implementado no município, pretende-se que o mesmo possa ser um modelo integrado, horizontalizado, contando com a participação da população em sua formulação, desenvolvimento e avaliação. Como estratégia de desenvolvimento deste modelo, optou-se pelas ações de atenção primária à saúde, uma vez que as mesmas configuram a porta de entrada dos serviços de saúde. A atuação com profissionais de nível médio é um fator facilitador deste processo, pois os mesmos desempenham um papel fundamental na organização dos serviços e na articulação com a população, por estarem mais próximos de sua realidade de vida.

Dados secundários sobre as condições sociais e de saúde da população foram coletados nesta fase.

O levantamento populacional da área para 1992, já realizado, compreendeu os seguintes aspectos: demográfico, sócio-econômico, condições de saúde e de saneamento. Estes foram coletados através de questionários especiais aplicados a cada família residente na área. $\mathrm{O}$ exame parasitológico das fezes foi realizado em toda a população, estando os dados em fase de apuração.

Taxas de infecção por Schistosoma mansoni para o único caramujo-vetor na área (Biomphalaria glabrata) foram obtidas para dois períodos 
do ano de 1992. Caramujos infectados foram encontrados em seis localidades, com taxas de infecção variando de 0,25 a $4,79 \%$.

$\mathrm{O}$ projeto de saneamento para a área de estudo foi elaborado nesta fase (FNS, 1992).

A fase de intervenção, iniciada em outubro de 1992, implica a manutenção das medidas de controle em toda a sua extensão e profundidade durante 36 meses (setembro de 1995). Especificamente, no momento atual, os pesquisadores das áreas de ciências sociais e de organização de serviços de saúde, ao lado do grupo de epidemiologia, estão intensificando suas ações.

A equipe das ciências sociais está em plena atividade de campo, desenvolvendo ações comunitárias entrosadas com as propostas de racionalização dos serviços de saúde. O processo de pesquisa participante já se iniciou e as ações desenvolvidas dizem respeito à capacitação da equipe técnica que vai atuar junto à população; à montagem de grupos de diagnóstico da situação; e à escolha de "informantes privilegiados" que possam traçar um painel político, econômico e social do município que ajude na construção do roteiro de entrevistas.

Simultaneamente, a equipe de epidemiologia desenvolve o primeiro levantamento coprológico desta fase. O primeiro tratamento médico está sendo realizado à medida que os exames de fezes vão se revelando positivos.

Os levantamentos de prevalência e o tratamento médico serão realizados em ciclos anuais durante a fase de intervenção (1992-1995). O primeiro ciclo desta fase estará concluído em setembro de 1993, quando será feita a primeira avaliação.

Embora as avaliações sejam contínuas, os seis últimos meses do projeto (1995-1996) estão reservados para a avaliação final. Nesse momento, todas as atividades que o grupo de pesquisa vinha realizando deverão ter sido transferidas para os serviços locais de saúde. A avaliação técnica e a determinação de custos deste projeto são essenciais para a sua reprodutibilidade.

Dependendo da sua viabilidade, seria desejável que o projeto desenvolvido na área de pesquisa fosse gradualmente estendido às demais áreas do município, podendo o mesmo se transformar em um modelo aplicável às demais regiões endêmicas do país.

\section{AGRADECIMENTOS}

Um trabalho desta natureza implica o envolvimento de várias instituições e de muitas pessoas, cuja lista seria muito longa e sujeita a omissões involuntárias. Por este motivo, limitamos os nossos agradecimentos à Fundação Oswaldo Cruz, ao Diretor da Escola Nacional de Saúde Pública (Prof. Paulo Buss) e ao Diretor da Escola Politécnica de Saúde Joaquim Venâncio (Dr. Antenor Amâncio); à Secretaria de Saúde do Estado do Espírito Santo (Dr. Luis Alberto Tavares, Secretário, e Dr. Erivelton Pires Martins, Superintendente Regional); à Prefeitura Municipal de Afonso Cláudio (Engo Methódio José da Rocha, Prefeito, e Enf. Marfisa Novaes, Secretária de Saúde); e à Fundação Nacional de Saúde (Dr. J. Tasso Alencar, Coordenador Regional, Dr. Luis J. Franzotti, Chefe da Equipe de Vetores e Endemias, Eng ${ }^{\circ}$ José Ribamar, e os guardas W. Gilberti, A. Carreta, A. C. Miranda, L. S. Matos e J. Pereira).

\section{RESUMO}

BARBOSA, F. S.; CRUZ, O. J.;

HOLLANDA, E.; SIQUEIRA, S. A. V.; CARVALHO, M.A. P.; GOMES, M. L. \& ALMEIDA, A. S. Modelo Alternativo para o C ontrole da E squistossomose: E stado A tual do Projeto no Espírito Santo, B rasil. Cad. Saúde Públ., Rio de Janeiro, 9 (1): 8589, jan/mar, 1993.

O trabalho que vem sendo desenvolvido em uma área rural do município de Afonso Cláudio (Espírito Santo) representa uma proposta alternativa aos atuais programas de controle. Este é um trabalho de pesquisa controlado, em integração interdisciplinar e multi-institucional, envolvendo várias entidades de pesquisa e de serviços. O modelo alternativo de controle da endemia conta com amplo envolvimento comunitário e com a 
organização dos serviços locais de saúde a nível primário (SUS). A pesquisa participante tem sido o ponto de partida metodológico que baliza os procedimentos de coleta e análise de dados e os de intervenção na realidade local. Os métodos de controle estão limitados ao tratamento médico individualizado e à melhoria das condições de saneamento. Estes métodos estão, evidentemente, integrados às ações sociais acima descritas. O projeto está dividido em três fases: pré-controle, controle (intervenção) e avaliação final. No momento, o mesmo entra em sua fase de intervenção, com duração prevista de três anos.

Palavras-Chave: Esquistossomose; Epidemiologia; Controle; Espírito Santo; Brasil

\section{REFERÊNCIAS BIBLIOGRÁFICAS}

BARBOSA, F. S. 1991. Modelo Alternativo para o Controle da Esquistossomose. Rio de Janeiro: Núcleo de Doenças Endêmicas Samuel Pessoa, Escola Nacional de Saúde Pública. (Mimeo.)

BARBOSA, F. S. \& COIMBRA Jr., C. E. A., 1992. Alternative Approaches in Schistosomiasis Control. Memórias do Instituto Oswaldo Cruz (no prelo).

FNS (Fundação Nacional de Saúde, Ministério da Saúde), 1992. Estudo de melhorias sanitárias em uma área de esquistossomose endêmica no município de Afonso Cláudio - Estado do Espírito Santo. Vitória: Fundação Nacional de Saúde, Coordenadoria do Estado do Espírito Santo. (Mimeo.)

SES-ES (Secretaria de Estado de Saúde do Espírito Santo), 1990. Modelo Assistencial de Saúde do Espírito Santo. Vitória: Secretaria de Estado de Saúde do Espírito Santo. (Mimeo.) 